10 Leake RD, Weitzman RE, Glatz TH, Fisher DA. Plasma oxytocin concentrations in men, nonpregnant, and pregnant women before and during spontaneous labor. F Clin Endocrinol Metab 1981;53:730-3.

11 Ferguson JKW. A study of the motility of intact uterus at term. Surg Gynecol Obstet 1941;73:359-66.

12 Debackere M, Peeters G, Tuyttens N. Reflex release of an oxytocic hormone by stimulation of genital organs in male and female sheep studied by a crossby stimulation of genital organs in male and female

13 Bates RG, Hell CW, Duncan A, Edmonds DK. Uterine activity in the second stage of labour and the effect of epidural analgesia. Br 7 Obstet Gynaecol stage of labour and

14 Doughty A. Selective epidural analgesia and the forceps rate. $\mathrm{Br} f$ Anaesth 1969;41:1058-62
15 Sellers SM, Hodgson HG, Mountford LA, Mitchell MD, Anderson ABM, Turnbull AC. Is oxytocin involved in parturition? $\mathrm{Br} \mathcal{F}$ Obstet Gynaecol 1981;88:725-9.

16 De Geest K, Thiery M, Piron Possuyt G, Vanden Driessche R. Plasma oxytocin in human pregnancy and parturition. $\mathcal{F}$ Perinat Med 1985;13:3-13. 17 Goodfellow CF, Studd C. The reduction of forceps in primigravidae with epidural analgesia - a controlled trial. Br f Clin Pract 1979;33:287-8.

18 Liston WA, Campbell AJ. Dangers of oxytocin induced labour to fetuses. BrMed f 1974; iii:606-7.

(Accepted 10 October 1989)

\title{
Hypernatraemic dehydration in patients in a large hospital for the mentally handicapped
}

\author{
N J Macdonald, K N McConnell, M R Stephen, M G Dunnigan
}

\begin{abstract}
Objective-To determine the prevalence of hypernatraemic dehydration and to assess the hydration and nutritional state of patients in a large hospital for the mentally and physically handicapped; also to assess the efficacy of an intervention programme to reduce the prevalence of hypernatraemic dehydration in the hospital.

Design-Prospective study of patients admitted with hypernatraemic dehydration from a large hospital for mentally and physically handicapped patients (hospital A) to a district general hospital between 1986 and 1988. In 1986 the hydration and nutritional state of a random sample of patients from hospital A was compared with a random sample of patients from a small hospital for the physically and mentally handicapped (hospital B) and with control groups from the community. The hydration of the patients from hospital $A$ examined in 1986 was reassessed in 1988 .
\end{abstract}

Patients - 12 Patients were admitted from hospital A to the district general hospital during 1986-8 (seven women, five men; age range 29-82). In 1986, 72 patients were randomly selected for the assessment of hydration and nutritional state from hospital A, 33 who required help with feeding and 39 who could feed independently. Fifty patients were similarly selected from hospital $B$, half of them requiring help with feeding. In 1988 the hydration state of 60 of the 72 patients from hospital was reassessed. Control values were taken from two published studies.

Interventions - In 1987 nursing staff in hospital A were asked to provide between 2.5 and 3.0 litres of fluid daily for all patients. The use of hypertonic enemas was discontinued, and the ratio of staff to patients was increased.

Main outcome measures-Serum concentrations of urea and electrolytes (hydration) and body mass index (nutritional state).

Results - Of the 10 patients admitted with hypernatraemic dehydration from hospital $A$ to the district general hospital in 1986, four died of intercurrent infection. No patients were admitted from hospital $B$ with hypernatraemic dehydration during the same time. In 1986 the hydration and nutritional state of patients in hospital $A$ were inferior to those in patients from hospital $B$ and control subjects from the community (serum urea concentrations were $6 \cdot 1$ (SD 1.8$) \mathrm{mmol} / \mathrm{l} v 5.5(1.9)$ and $5.6(0.4) \mathrm{mmol} / \mathrm{l}$, respectively) $50 \%(36 / 72)$ of patients in hospital $A$ had a body mass index $\leqslant 20$ compared with $34 \%$ (17/ $50)$ of patients from hospital $B$ and $12 \%(1141 / 9434)$ of control subjects). After the initiation of the preventive programme only one patient was admitted with hypernatraemic dehydration in each of the years 1987 and 1988. The mean serum urea concentration of the 60 patients who were reassessed in 1988 fell significantly between 1986 and 1988 from $6 \cdot 1(\mathrm{SD} 1.8) \mathrm{mmol} / \mathrm{l}$ to $5 \cdot 7(2 \cdot 1) \mathrm{mmol} / \mathrm{l}$, the value in a control group matched for age and sex.

Conclusions-Hypernatraemic dehydration, subclinical underhydration, and undernutrition were common in a large hospital for the mentally and physically handicapped. The problem of hypernatraemic dehydration was successfully dealt with by the hospital management team. Similar problems may be encountered in hospitals for patients who are mentally and physically handicapped and mentally ill, including psychogeriatric units.

\section{Introduction}

Hypernatraemic dehydration occurs when the loss of free water from the kidney, gastrointestinal tract, skin, and mucous membranes exceeds the intake of water. ${ }^{1}$ Hypernatraemia (usually defined as a serum sodium concentration greater than $150 \mathrm{mmol} / \mathrm{l}$ ) has a mortality approaching $60 \%$ in adults and contributes to the morbidity and mortality of the underlying disease. ${ }^{2}$ Patients whose response to thirst is blunted or whose access to fluids is limited are particularly at risk of hypernatraemic dehydration. This includes infants ${ }^{3}$ and confused or demented elderly people. ${ }^{45}$

People who are mentally handicapped, mentally ill, and physically handicapped might also be expected to be at risk of hypernatraemic dehydration. There are reports of this condition in individual psychotic patients $^{6}$ and in the rare disorder of hypodipsic hypernatraemia associated with various congenital or acquired brain diseases. ${ }^{7}$ Hypernatraemic dehydration resulting from predominantly environmental factors in psychiatric institutions has not been previously described.

In January 1986 three patients with hypernatraemic dehydration were admitted to the medical division of this hospital from a large hospital for the mentally and physically handicapped (hospital A). Since then all admissions from hospital A to this hospital have been monitored to detect further cases of hypernatraemic dehydration. The reasons for its occurrence have been investigated and effective preventive measures implemented.

\section{Patients and methods}

In March 1986 a venous blood sample was taken from 72 mentally handicapped patients from 14 wards in hospital A. Serum concentrations of electrolytes, 
urea, creatinine, and proteins were determined by a sequential multiple analyser with computer (Technicon Instruments, Basingstoke) multichannel autoanalyser. Thirty three patients ( 21 men, 12 women; median age 43; range 24-92) were also severely physically handicapped and needed help with feeding; the remaining 39 ( 21 men, 18 women; median age 49; range 24-75) could feed independently. Sixty patients from both groups were reassessed in March 1988 to measure the effectiveness of the preventive programme (see below). The results were compared with those in a control group from the community matched for age and sex. ${ }^{8}$

As an index of nutritional state the body mass index (weight $(\mathrm{kg}) /(\text { height }(\mathrm{m}))^{2}$ ) of each patient was derived and compared with the body mass indices in a group of 9434 normal British men and women aged 16-64. ${ }^{9}$ The nurse staffing levels, intake of fluids by patients, and the use of hypertonic enemas were also assessed.

In September 1986 these investigations were repeated in a small hospital containing 95 physically and mentally handicapped patients (hospital B). Blood was obtained from 50 patients, of whom 25 were severely physically handicapped and required help with feeding ( 10 men, 15 women; median age 49 , range 20-67) and 25 could feed independently (six men, 19 women; median age 56, range 32-72).

Statistical comparison of patients and control groups was carried out with Student's paired or unpaired $t$ test for normally distributed results and the Wilcoxon rank sum or Wilcoxon signed rank test for non-normally distributed paired and unpaired results respectively. The distributions of body mass indices were compared with the $\chi^{2}$ test.

\section{Results}

ADMISSIONS FOR HYPERNATRAEMIC DEHYDRATION

In 1986,10 patients were admitted to this hospital from hospital A with hypernatraemic dehydration (serum sodium concentration $>150 \mathrm{mmol} / \mathrm{l}$ ) (table I). All 10 patients were highly dependent and required help with feeding. A further four patients were admitted with biochemical evidence of dehydration with a normal serum sodium concentration (serum urea concentration $>10 \mathrm{mmol} / \mathrm{l}$, serum creatinine concentration $<250 \mu \mathrm{mol} / \mathrm{l}) .{ }^{10}$

In nine of the 10 patients with hypernatraemic dehydration the condition seemed to have been precipitated by intercurrent infection. The repeated use of hypertonic enemas seemed to be a contributory factor in three patients. "In all 10 hypernatraemic patients nursing staff had observed increasing lethargy with feeding difficulties for a variable period of days and weeks followed by the rapid onset of drowsiness and mental confusion. All patients showed evidence of hypotension and oligaemic shock on admission to this hospital.
TABLE II - Serum urea and creatinine concentrations in patients from hospitals $A$ and $B$ compared with values in controls matched for age and sex. ${ }^{*}$ Values are means $(S D)$

\begin{tabular}{|c|c|c|}
\hline Group & $\begin{array}{c}\text { Serum urea } \\
(\mathrm{mmol} / \mathrm{l})\end{array}$ & $\begin{array}{l}\text { Serum creatinine } \\
\qquad(\mu \mathrm{mol} / \mathrm{l})\end{array}$ \\
\hline \multicolumn{3}{|c|}{ Hospital A } \\
\hline Combined $(n=72)$ & $6 \cdot 1(1 \cdot 8)^{\star}$ & $81(21)$ \\
\hline Control $(\mathrm{n}=72)$ & $5 \cdot 6(1 \cdot 4)$ & $87(18)$ \\
\hline Requiring help in feeding $(n=33)$ & $6 \cdot 0(2 \cdot 0)$ & $71(18)^{\star \star}$ \\
\hline Control $(n=33)$ & $5 \cdot 7(1 \cdot 3)$ & $91(19)$ \\
\hline Independent $(\mathbf{n}=39)$ & $6 \cdot 3(1 \cdot 6)^{\star}$ & $89(19)$ \\
\hline Control $(n=39)$ & $5 \cdot 4(1 \cdot 6)$ & $83(17)$ \\
\hline \multicolumn{3}{|c|}{ Hospital B } \\
\hline Combined $(\mathrm{n}=50)$ & $5 \cdot 5(1.9)$ & $79(19)$ \\
\hline Control $(n=50)$ & $5 \cdot 7(0 \cdot 1)$ & $84(18)$ \\
\hline Requiring help in feeding $(n=25)$ & $5 \cdot 4(1.8)$ & $74(16)^{\star}$ \\
\hline Control $(n=25)$ & $6 \cdot 0(1 \cdot 1)$ & $86(21)$ \\
\hline Independent $(\mathbf{n}=25)$ & $5 \cdot 6(2 \cdot 0)$ & $84(21)$ \\
\hline Control $(n=25)$ & $5 \cdot 3(0.9)$ & $83(14)$ \\
\hline
\end{tabular}

Six patients were resuscitated by intravenous rehydration, with raised serum urea and creatinine concentrations returning to normal. In four patients who died clinical investigations and findings at necropsy showed the principal causes of death (apart from hypernatraemic dehydration) to be staphylococcal septicaemia (table I, case 2), septicaemia caused by Escherichia coli resulting from a perforated diverticulum of the sigmoid colon (table I, case 3), acute bronchopneumonia in association with atonic colonic dilatation (table I, case 6), and bronchopneumonia with acute renal failure secondary to acute tubular necrosis caused by severe dehydration (table I, case 8 ).

Survey of the case records in hospital B showed no previous transfers of patients with hypernatraemic dehydration to this hospital.

\section{SURVEYS OF PATIENTS}

The serum urea concentrations in seven of the 72 $(10 \%)$ patients from hospital A were above the upper $95 \%$ confidence limit of the reference range in a normal control group from the community matched for age and $\operatorname{sex}^{8}(p<0.001)$ (table II). All 72 patients had normal serum creatinine concentrations. Patients from hospital A had a significantly higher mean serum urea concentration (but not a significantly higher mean serum creatinine concentration) than the control group $^{8}$ : this difference attained significance only in the patients who could feed independently. The findings show a significant degree of underhydration in the patients from hospital A. The significantly lower mean serum creatinine concentration in the patients who needed help with feeding reflects the lower muscle mass of this comparatively underweight group compared with controls from the community ${ }^{8}$ (see below).

Only two of the $50(4 \%)$ patients from hospital B had serum urea concentrations above the upper $95 \%$ confidence limit of the control group ${ }^{8}$ (NS). All 50 patients had normal serum creatinine concentrations. There

TABLE I - Details of patients admitted from hospital A to Stobhill Hospital with hypernatraemic dehydration during 1986-8

\begin{tabular}{|c|c|c|c|c|c|c|c|}
\hline Case No & $\begin{array}{l}\text { Sex and age } \\
\text { (years) }\end{array}$ & $\begin{array}{c}\text { Year of } \\
\text { admission }\end{array}$ & $\begin{array}{l}\text { Serum sodium } \\
(\mathrm{mmol} / \mathrm{l})\end{array}$ & $\begin{array}{l}\text { Serum urea } \\
(\mathrm{mmol} / \mathrm{l})\end{array}$ & $\begin{array}{l}\text { Serum creatinine } \\
(\mu \mathrm{mol} / \mathrm{l})\end{array}$ & Precipitating factors & Outcome \\
\hline 1 & F30 & & 155 & 14 & 247 & Respiratory infection & Survived \\
\hline 2 & M82 & & 177 & 29 & 276 & Staphylococcal septicaemia & Died \\
\hline 3 & F75 & & 151 & 52 & 572 & $\begin{array}{l}\text { Escherichia coli septicaemia and } \\
\text { perforated colonic diverticulum }\end{array}$ & Died \\
\hline 4 & M65 & & 150 & 19 & 119 & Dysphagia; cause unidentified & Survived \\
\hline 5 & F74 & & 157 & 17 & 348 & Respiratory infection & Survived \\
\hline 6 & M51 & 1986 & 171 & 25 & 173 & $\begin{array}{l}\text { Bronchopneumonia and atonic colonic } \\
\text { dilatation; phosphate enemas }\end{array}$ & Died \\
\hline 7 & M29 & & 184 & 39 & 474 & Pyrexial illness; phosphate enemas & Survived \\
\hline 8 & F65 & & 197 & 84 & 1128 & $\begin{array}{l}\text { Bronchopneumonia and acute } \\
\text { tubular necrosis }\end{array}$ & Died \\
\hline 9 & F48 & & 168 & 35 & 509 & Pyrexial illness; phosphate enemas & Survived \\
\hline 10 & F36 & & 150 & 13 & 70 & Respiratory infection & Survived \\
\hline 11 & F56 & 1987 & 151 & 10 & 54 & $\begin{array}{l}\text { Respiratory infection; anticonvulsant } \\
\text { toxicity }\end{array}$ & Survived \\
\hline 12 & M54 & 1988 & 153 & 30 & 707 & Chronic renal failure & Survived \\
\hline
\end{tabular}


TABLE III-Body mass indices in patients from hospitals $A$ and $B$ and in control subjects from community. ${ }^{\circ}$ Values are numbers (percentages) of patients or subjects

\begin{tabular}{|c|c|c|c|c|c|c|}
\hline \multirow[b]{2}{*}{ Group } & \multicolumn{6}{|c|}{ Body mass index } \\
\hline & $\leqslant 20$ & $21-25$ & $26-30$ & $31-35$ & $36-40$ & $>40$ \\
\hline & & Hospital A & & & & \\
\hline Requiring help in feeding & $25(76)$ & $4(12)$ & $2(6)$ & $2(6)$ & & \\
\hline Independent & $11(28)$ & $\begin{array}{c}11(28) \\
\text { Hospital B }\end{array}$ & $11(28)$ & $6(15)$ & & \\
\hline Requiring help in feeding & $11(44)$ & $12(48)$ & $2(8)$ & & & \\
\hline Independent & $6(24)$ & $9(36)$ & $6(24)$ & $3(12)$ & & $1(4)$ \\
\hline Control & $1141(12)$ & $\begin{array}{l}\text { Community } \\
4958(53)\end{array}$ & $2669(28)$ & $521(6)$ & $145(2)$ & \\
\hline
\end{tabular}

were no significant differences in the mean serum urea or creatinine concentrations of patients from hospital B as a whole compared with the control group from the community. ${ }^{8}$ Again, the significantly lower mean serum creatinine concentration in patients who required help with feeding reflects their lower muscle mass.

Patients from hospital A had a significantly higher mean serum urea concentration (but not a significantly higher mean serum creatinine concentration) than those from hospital B $(p<0.05)$. Differences between the subgroups were not significant. The results suggest that the hydration of patients from hospital $B$ was superior to that of their counterparts from hospital A.

\section{NUTRITIONAL STATE}

As judged by body mass indices all 72 patients from hospital A regardless of whether they needed help with feeding were significantly leaner than the controls from the community (in all three groups $p<0.001$; table III). Seven $(10 \%)$ of the patients from hospital $\mathrm{A}$ had low total serum protein concentrations $(<62 \mathrm{~g} / \mathrm{l})$ and eight $(11 \%)$ low serum albumin concentrations $(<36$ $\mathrm{g} / \mathrm{l})$.

Patients from hospital B were significantly leaner than controls from the community, ${ }^{9}$ but the level of significance was lower than that in the patients from
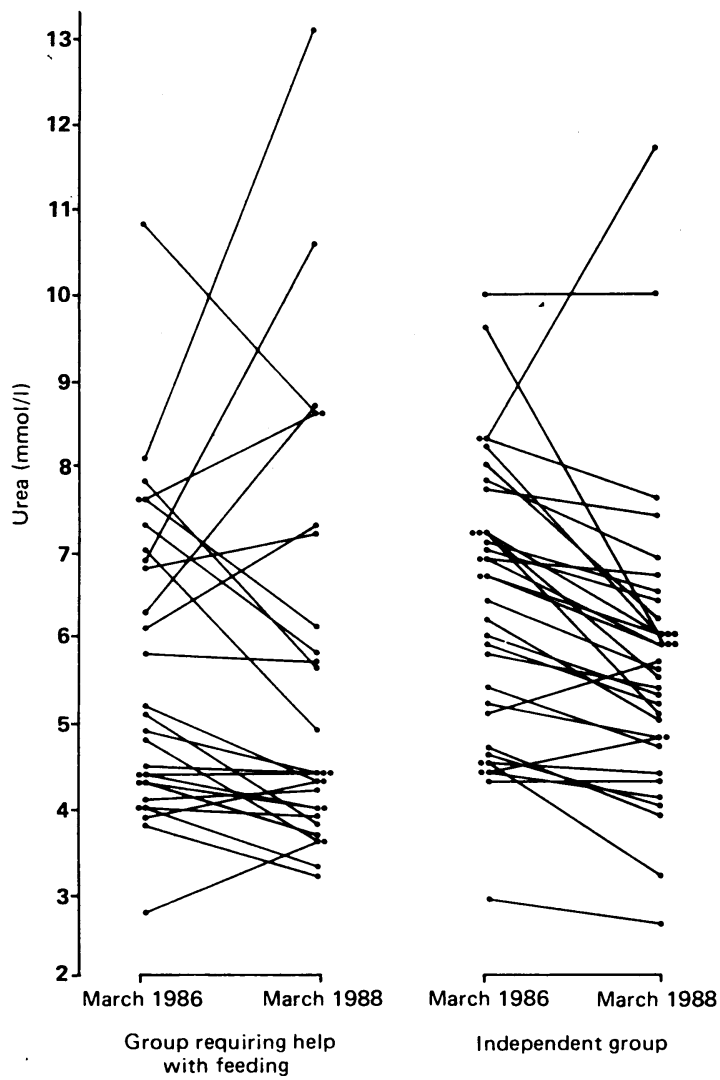

Response of serum urea concentrations to increased fluid intakes in patients requiring and not requiring help with feeding in hospital $A$ hospital A $(\mathrm{p}<0.01$; table III). The patients who needed help with feeding were also significantly leaner than the controls ${ }^{9}(p<0.001)$ but significantly heavier than their counterparts in hospital $A(p<0 \cdot 01)$. Five of the $50(10 \%)$ patients from hospital $\mathrm{B}$ had low total serum protein concentrations $(<62 \mathrm{~g} / \mathrm{l})$ and seven $(14 \%)$ low serum albumin concentrations $(<36 \mathrm{~g} / \mathrm{l})$.

\section{FACTORS CONTRIBUTING TO DEHYDRATION}

In March 1986 hospital A contained 979 patients, of whom $197(20 \%)$ were highly dependent and required help with feeding. The number of highly dependent patients in the 10 wards containing most of the highly dependent patients ranged from 10 to 17 (median 15). The number of independent patients in these wards ranged from 8 to 36 (median 32). Each ward was usually staffed by one qualified nurse (registered or enrolled) and three unqualified care assistants (nurse to patient ratio about $1: 10$ ). Staffing levels were clearly inadequate, and staff were often moved at short notice to provide cover for sickness or absences due to holidays.

In many wards fluid intakes were low (estimated at between 1.0 litre and 1.5 litres daily per head). Twenty five of the $33(76 \%)$ patients who required help with feeding and 12 of the 39 (31\%) patients who did not received occasional or regular hypertonic phosphate enemas for constipation. Many wards were warm $\left(75^{\circ} \mathrm{F}\right.$ or over), leading to increased insensible water loss.

Staff to patient ratios were better in hospital B (about 1:5). Fluid intake was monitored and a target of about 3 litres daily was set for patients who needed help with feeding. Hypertonic enemas were not used.

\section{PREVENTIVE MEASURES}

After identification of the problem the unit management team initiated prompt preventive measures. Various fluids were made available on demand and nursing staff were set a target of giving patients who required help with feeding between 2.5 and 3.0 litres of them daily. The use of hypertonic phosphate enemas was stopped. Additional nursing staff were recruited as part of the Greater Glasgow Health Board's mental health strategy for the hospital.

In January 1988 the hospital was revisited, nursing staff being then aware of the need to provide ample fluids for dependent patients. Several nurses commented spontaneously that constipation was now much less of a problem. In most wards staffing had been increased to two qualified nurses and three care assistants. Sixty of the 72 patients assessed in March 1986 were reassessed in March 1988. Mean serum urea concentration fell from $6 \cdot 1$ (SD 1.8) mmol/1 in March 1986 to $5 \cdot 7(2 \cdot 1) \mathrm{mmol} / \mathrm{l}$ in March $1988(\mathrm{p}<0.001$; figure). The results show that the hydration of patients was improved: in March 1988 the mean serum urea concentration was identical with that in a control group from the community matched for age and $\operatorname{sex}^{8}(5 \cdot 7$ $(1 \cdot 2) \mathrm{mmol} / \mathrm{l})$. This reduction was also significant in patients who did not need help with feeding $(p<0 \cdot 001)$.

The number of patients admitted with hypernatraemic dehydration to this hospital from hospital A fell from 10 in 1986 to one in 1987 (associated with anticonvulsant toxicity) and one in 1988 (associated with chronic renal failure). Four patients were admitted with biochemical evidence of dehydration with a normal serum sodium concentration in 1986, five in 1987 , and two in 1988, associated with a range of diseases.

\section{Discussion}

Hypernatraemic dehydration was common in hospital A in 1986. The contribution of individual risk factors to the occurrence of this dangerous condition 
is unquantifiable as several were operating simultaneously in the environment of hospital A. These proved particularly hazardous for patients whose ability to experience thirst, to express a desire for fluids, or to obtain fluids was limited by severe mental and physical handicap. One qualified nurse and three care assistants, fed, toiletted, and dressed up to 17 highly dependent patients who could not drink or eat without help and supervised up to 32 independent patients. Fluid intakes were barely adequate, and in some patients fluid depletion may have been accentuated by hypertonic enemas, which were used mainly in patients who needed help with feeding. The condition of these patients was thus readily precipitated into severe dehydration by intercurrent infection. Excessive use of psychotropic drugs (major and minor tranquillisers, anticonvulsants, and lithium) did not seem to be a significant risk factor for hypernatraemic dehydration in patients from hospital A, with one exception (see above).

Patients from hospital A were leaner than both patients from hospital $B$ and controls from the community, and nearly three quarters of those from hospital A who required help with feeding were underweight ${ }^{9}$ (body mass index $\leqslant 20$; table III). Though in many patients this reflects disuse atrophy of muscles associated with cerebral palsy at birth, direct observation suggested that the intakes of food were often inadequate given the difficulty in feeding highly dependent patients when staffing is inadequate.

The appointment of a senior dietitian to hospital A has permitted a preliminary assessment of patients' dietary intakes. A one day weighed dietary survey of the food intakes of six patients chosen at random from each of eight representative wards was completed in February 1989. The mean (SD) energy intake of 28 patients who could feed independently (6711 (1201) $\mathrm{kJ}$ ), although suboptimal, was significantly greater than that of 20 dependent patients who required help with feeding (5092 (1607) kJ; $<<0 \cdot 001)$; this seemed to be inadequate.

In March 1989, 69 underweight independent and dependent patients were provided with high protein nutritional supplements in soups and puddings and as drinks. These were designed to provide an extra $60 \mathrm{~g}$ protein and $2510 \mathrm{~kJ}$ for each patient. After one month all but three of the 69 patients gained weight from a mean of $47 \cdot 7(9 \cdot 8) \mathrm{kg}$ to that of $49 \cdot 4(9 \cdot 9) \mathrm{kg}(\mathrm{p}<0.001$; M Kennedy, personal communication). Taken with the body mass indices, the results suggest that a proportion of patients in hospital A (particularly those requiring help with feeding) were undernourished. The longer term results of the nutritional supplement programme and of a recently completed five day weighed dietary survey of a further group of patients from hospital A will be published in due course.

Hospital B had no record of patients being admitted to our hospital with hypernatraemic dehydration. As noted, the hydration and nutritional states of patients from hospital B were superior to those of patients from hospital A. These differences are attributable to better staffing levels, higher intakes of fluid, lower ambient ward temperatures, and the lack of use of hypertonic enemas.

The prompt action of the unit management team resulted in a considerable reduction in the number of patients admitted with hypernatraemic dehydration in 1987 and 1988 accompanied by a significant improve- ment in the hydration of patients. This response suggests that the former prevalence of hypernatraemic dehydration in the hospital was mainly due to environmental factors.

We have found no previous reports of environmentally determined hypernatraemic dehydration in long stay hospitals for the mentally handicapped, mentally ill, and physically handicapped in the United Kingdom or elsewhere. A report of hypernatraemic dehydration in elderly patients in a private nursing home in the United States described this condition as "an indicator of neglect." There was no evidence of deliberate neglect of patients in hospital A, but the finding of hypernatraemic dehydration drew attention to major inadequacies in patient care. Responsibility for this state of affairs lies with a series of previous senior NHS managements and not with the hospital's nursing and medical staff, who have been struggling for years with grossly inadequate resources. These deficiencies are being slowly rectified by the Greater Glasgow Health Board's mental health strategy for the hospital.

The computer in the biochemistry department of our hospital identified 10 patients in 1986 who had severe hypernatraemic dehydration (serum sodium concentration $>170 \mathrm{mmol}$ ). Of these, four came from hospital A (979 patients), three from a neighbouring psychiatric hospital (765 patients), and only three from homes in the hospital's catchment area (estimated population 210000 ). The possibility of life threatening hypernatraemic dehydration should be considered wherever mentally handicapped, mentally ill, or physically handicapped patients are looked after in large institutions, particularly when the institutions are isolated from acute district general hospitals and nursing and medical staff are few. Psychogeriatric patients may also be at risk. The results from hospital B show that small, adequately staffed, and efficiently managed hospitals are well equipped to provide physical care for highly dependent, mentally and physically handicapped patients.

We thank the medical, nursing, and administrative staff of Lennox Castle (hospital A) and Broomhill Hospitals (hospital B) for their cooperation in making this investigation possible. We also thank Mrs Marissa Kennedy, senior dietitian, Lennox Castle Hospital, who carried out the dietary investigations reported in this paper.

1 Ross EJ, Christie SBM. Hypernatraemia. Medicine 1969;48:441-73.

2 Arieff AI. Central nervous system manifestations of disordered sodium metabolism. Clin Endocrinol Metab 1984;13:269-94.

3 Finberg L. Hypernatremic (hypertonic) dehydration in infants. $N$ Engl $f$ Med 1973;289:196-8

4 Himmelstein DU, Jones AA, Woolhandler S. Hypernatremic dehydration in nursing home patients. An indicator of neglect. F Am Geriatr Soc 1983; 31:466-71.

5 Snyder NA, Feigal DW, Arieff AI. Hypernatremia in elderly patients. A heterogeneous, morbid and iatrogenic entity. Ann Intern Med 1987;107:309. 19.

6 Farley PC, Lau K-Y, Suha S. Severe hypernatremia in a patient with psychiatric illness. Arch Intern Med 1986;146:1214-5.

7 Hammond DN, Moll GW, Robertson GL, Chelmicka-Schorr MD. Hypodipsic hypernatremia with normal osmoregulation of vasopressin. $N$ Engl $7 \mathrm{Med}$ $1986 ; 315: 433-6$

8 Gardner MD, Scott R. Age- and sex-related reference ranges for eight plasma constituents derived from randomly selected adults in a Scottish new town J Clin Pathol 1980;33:380-5.

9 Knight I. The heights and weights of adults in Great Britain. London: HMSO, 1984:33

10 Morgan DB, Carver ME, Payne RB. Plasma creatinine and urea: creatinine ratio in patients with raised plasma urea. BrMed f 1977;ii:929-32.

11 Reynolds JEF. Martindale. The Extra Pharmacopoeia. 28th ed. London: Pharmaceutical Press, 1982:641.

(Accepted 17 October 1989) 